\title{
PREVALENCE OF MAXILLARY CANINE IMPACTION IN AN EGYPTIAN POPULATION: A RETROSPECTIVE STUDY
}

\author{
Hanady M. Samih ${ }^{1}$, Sherif E. Zahra ${ }^{2}$, Khalid S. Aboulazm ${ }^{3}$
}

\begin{abstract}
A6stract
Objective: To determine the prevalence of maxillary impacted canines in Egyptian population and its relativity to gender, location, and side distribution.
\end{abstract}

Materials and methods: Retrospective cross-sectional study of 7730 digital panoramic radiographs collected from Alexandria city in Egypt. The sample was examined for the presence of maxillary impacted canines. The radiographs were selected from the records of several private dental clinics and the archive of a radiographic center.

Results: Among the panoramic radiographs analyzed, 229 radiographs had at least one maxillary canine impaction with a prevalence of $2.96 \%$. The percentage of impacted canines in males was $36.24 \%$ and in females was $63.76 \%$. A higher number of impactions were seen unilaterally $82.1 \%$ than bilaterally $17.9 \%$. Right side impactions (42.79\%) were less common than left side impactions (75.1\%) in relation to the total number of radiographs with canine impactions. When including the unilateral impactions onfy, right side impactions were $24.89 \%$ while the left side impactions were $57.2 \%$.

Conclusions: The prevalence of maxillary impacted canines in the Egyptian population was found to be 2.96\% of the sample collected from Alexandria city which lies within the range reported in other populations. The maxillary canine impactions occurred more in females, unilaterally and on the left side.

Keywords: epidemiology, maxillary canines, panoramic radiography, prevalence, tooth impaction.

\section{1 | INTRODUCTION}

Tooth impaction is a pathological problem commonly found in dental practice. It is a condition in which a tooth is completely or incompletely embedded in the alveolus due to malposition or obstruction in its path of eruption into the oral cavity and is not expected to erupt completely into its normal functioning position when assessed clinically and with radiographs. A tooth is considered impacted when its eruption is delayed for more than two years following its physiological eruption time. There are wide variations in impacted teeth among individuals; the most prevalent impacted teeth are third molars, upper canines, upper central incisors, and upper premolars, respectively. ${ }^{1}$ Impacted teeth are asymptomatic but can contribute to several complications that compromise tooth aesthetics and functional outcomes. They can cause displacement and/or external root resorption of the neighbouring teeth, shortening of the arch perimeter and cystic lesions while in partial eruption cases they can trigger pain, infection, and trismus. ${ }^{2}$

The permanent canines are considered the most important teeth as they play an important role in aesthetics, functional occlusion, and arch development. The canine guidance disengages posterior teeth in lateral mandibular movement, thus protects the occlusion by reducing the chances of muscular dysfunction and temporomandibular disorders. ${ }^{3}$ The maxillary canine is of high significance; being anchored by its longest root in the maxilla, supports anterior and posterior arch segments, is hardly absent, has low susceptibility to caries in addition to its valuable functional and aesthetic qualities. They can be impacted either bilaterally or unilaterally and facially or

\footnotetext{
${ }^{1}$ Assistant Professor, Department of Orthodontics, Faculty of Dentistry, Suez Canal University, Ismailia, Egypt.

${ }^{2}$ Assistant Professor, Department of Orthodontics, Faculty of Dentistry, Suez Canal University, Ismailia, Egypt.

${ }^{3}$ Assistant Professor, Department of Orthodontics, Faculty of Dentistry, Pharos University, Alexandria, Egypt.
} 
palatally. The fact that maxillary canines are the last teeth to erupt contributes to their increased prevalence of impaction. ${ }^{4}$

Researchers believed the genetic and guidance theories for tooth impaction. The genetic theory shows the canine impaction is mainly due to genetic origin and usually accompanied by other tooth anomalies in size, shape, and numbers. Many studies reported the association of the palatally impacted teeth with lateral incisor anomalies, hypoplastic enamel, and infra-occlusal deciduous molars. The guidance theory suggests that odontomas, supernumerary teeth and missing lateral incisors obstruct the eruption of canines. Some investigators stated that the labial impaction is basically due to lack of eruption space while the palatal impaction is mostly due to a genetic origin. ${ }^{5}$

The causes of canine impaction can be categorized into localized and generalized factors. The generalized factors incorporate abnormal muscle pressure, febrile diseases, radiation, endocrine deficiencies, and vitamin $\mathrm{D}$ deficiency. While multiple local factors may be responsible for maxillary canine impaction as crypt displacement, retained or premature loss of the deciduous canine, long eruption path, tooth size-arch length discrepancy, absent or short rooted upper lateral incisor, alveolar cleft, cysts, or tumours, ankylosis, and an iatrogenic or idiopathic cause. ${ }^{6}$

Many researchers assessed the prevalence of maxillary canine impaction in several populations and had different findings in their studies. It is important to know the prevalence of maxillary canine impaction in a local population to help orthodontists and pedodontists understand the preventive and interceptive treatment protocols needed. The current study was performed to investigate the prevalence of canine impaction in the Egyptian population, any gender difference, their location, and side distribution in maxillary arch.

\section{2 | MATERIALS AND METHODS}

The present study is a retrospective crosssectional study performed using digital panoramic radiographs collected from Alexandria city in Egypt. The Research Ethics Committee of Faculty of Dentistry, Alexandria university approved the study protocol under reference number IORG0008839 (0143). Sample size was estimated based on assuming 95\% confidence level and $80 \%$ study power. Precision was set at $1 \%$ for prevalence below $10 \%$. Total sample size was calculated by Raosoft sample size calculator (online) to be a minimum of 726 cases.

A total of 8250 radiographs were obtained from the archives of a radiographic centre and several private dental clinics from June 2016 till June 2020. The inclusion criteria included patients' radiographs of age 15 years and above with all the permanent teeth erupted and were clear radiographs with good quality for proper diagnosis. Any radiograph with one of the following conditions was excluded from the study; age below 15 years, missing permanent canine, any pathological conditions (cysts and tumours) within premaxilla, maxillofacial surgeries, and poor-quality radiographs. After applying the inclusion and exclusive criteria, only 7730 radiographs were selected. The included radiographs were examined by two orthodontists to detect any maxillary impacted canine. The data obtained underwent interexaminer reliability. No significant difference $(\mathrm{P}>0.05)$ was found. The data collected was analysed to calculate the prevalence of impacted maxillary canine and to show any differences in the grouping of impacted canines when sorted by gender, location (unilateral or bilateral) and side distribution (left or right). 


\section{3 | RESULTS}

The study incorporated a total number of 7730 panoramic radiographs, 229 of them showed one or more impacted canines (Figure 1), the mean age of patients was 24.8 years, ranging between 15 and 40 years. The overall prevalence of canine impaction was $2.96 \%$ (Table

$1)$.

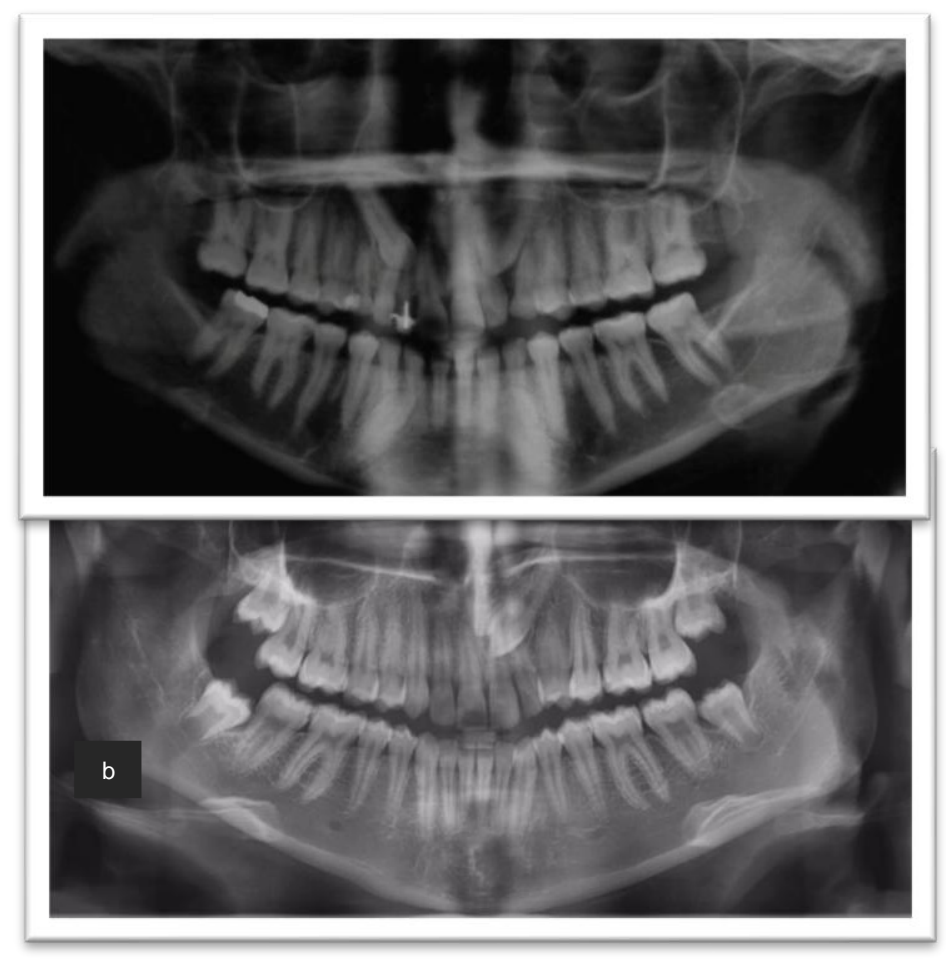

FIGURE 1 shows; a) maxillary bilateral canine impactions and, b) maxillary left canine impaction.

TABLE 1 Distribution of the positive radiographs with maxillary canine impactions among the total number of radiographs.

\begin{tabular}{lll} 
& Number & Prevalence \% \\
$\begin{array}{l}\text { Total number of } 7730 \\
\text { examined radiographs }\end{array}$ & \\
$\begin{array}{l}\text { Radiographs with } 229 \\
\text { impacted canines }\end{array}$ & & $2.69 \%$ \\
\hline
\end{tabular}

Further analysis showed distribution of the positive radiographs with impacted canines regarding their demographic data (Table 2). There was a difference in number of males $(36.24 \%, \mathrm{n}=83)$ and females $(63.76 \%$, $\mathrm{n}=146$ ), (Figure 2). A higher number of unilateral canine impactions were seen in maxillary arch $(82.1 \%, \mathrm{n}=188)$ compared to bilateral canine impactions $(17.9 \%, \mathrm{n}=41)$, (Figure 3). Whereas the maxillary impacted canines located on the right side that occurred in 98 radiographs $(42.79 \%)$ were less than those found on the left side that presented in 172 radiographs $(75.1 \%)$ of the total sample with impacted canines (including the 41 bilateral cases). Regarding unilateral impactions only $(82.1 \%, \quad \mathrm{n}=188), \quad 57$ radiographs $(24.89 \%)$ had impactions on the right side while 131 radiographs $(57.2 \%)$ had impactions on the left side (Figure 4). 
$\boldsymbol{T A B L E} 2$ Distribution of the positive radiographs with maxillary canine impactions regarding their demographic data.

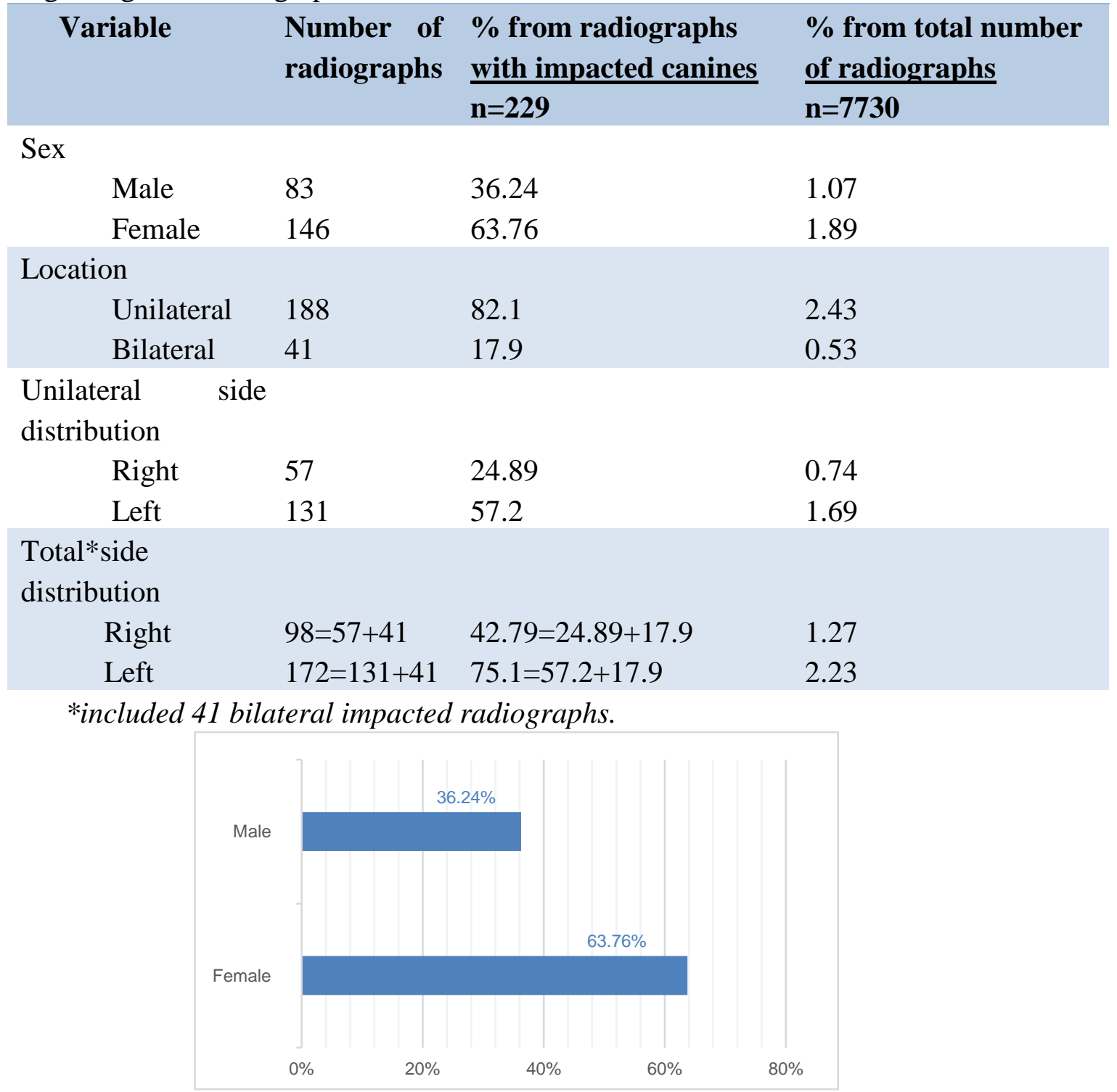

FIGURE 2 shows the percentage of male to female with maxillary canine impactions.

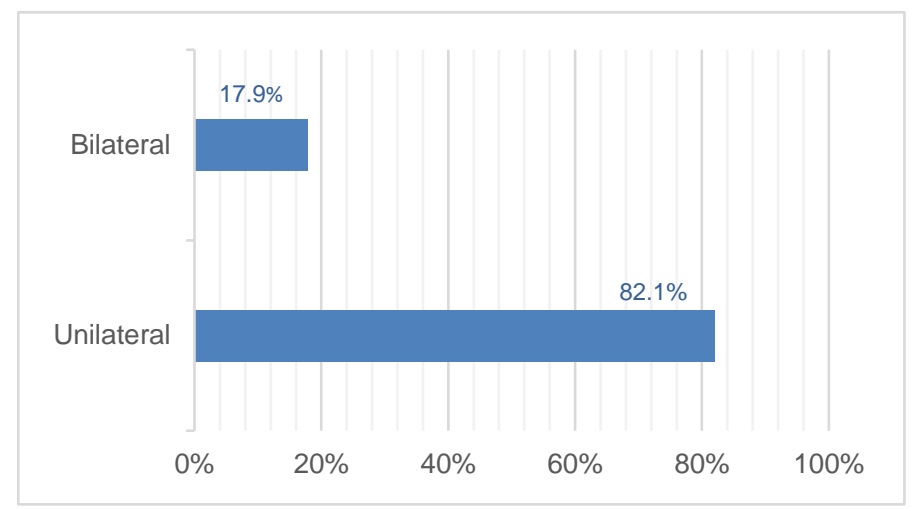

FIGURE 3 shows the percentage of the unilateral to the bilateral maxillary canine impactions. 


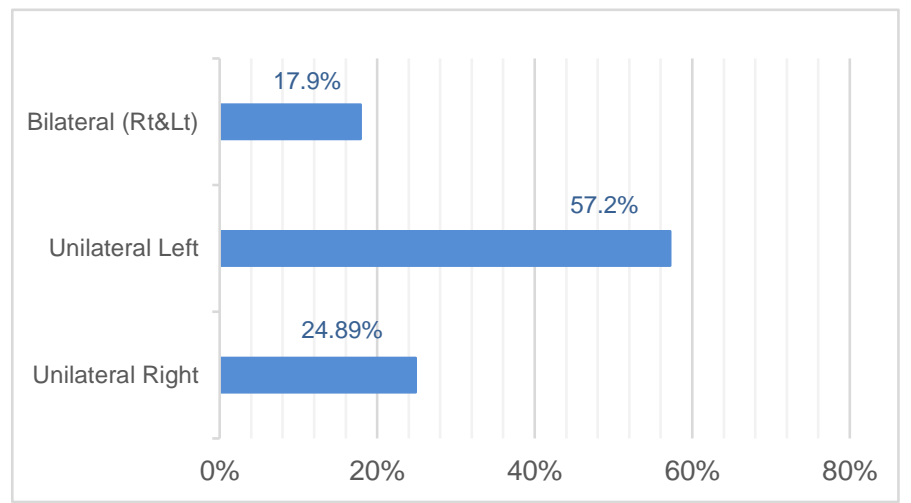

FIGURE 4 shows the percentage of the unilateral right side to the unilateral left side maxillary canine impactions.

\section{4 | DISCUSSION}

Maxillary canines have the longest development period and path from the point of formation till they reach their final position in full occlusion. They start to develop at 4-5 months and erupt at the age of 12 years. The impaction of maxillary canine teeth is assigned to its early crown formation and the long eruption path. Mandibular canine impaction is rare and occurs significantly less than maxillary canine. The prevalence of canine impaction in the maxillary arch was 20 times more common than in mandibular arch. ${ }^{7}$ Some authors have cited that the highest prevalence was found in western societies as $9.9 \%$ in Australian population and $8.8 \%$ in Greek population while the lowest prevalence was in Japan at $0.27 \%{ }^{8}$

The present study found the prevalence of impacted maxillary canines in Egyptian population was $2.96 \%$ where the study sample was collected from the city of Alexandria. This prevalence lies within the range $1.2 \%$ to $8.4 \%$ as reported by other studies where maxillary canine impaction was $4.71 \%$ regarding the 568 Croatian participants. ${ }^{9}$ Also, Gashi et al. ${ }^{10}$ analysed 8101 Kosovari radiographs and found $1.62 \%$ incidence for maxillary canine impactions. Furthermore, a research in Turkey stated that $3.27 \%$ of the examined 2900 patients had impacted maxillary canines. ${ }^{7}$ Camilleri ${ }^{11}$ carried a pilot study on 468 Maltese young school children which revealed $4.4 \%$ prevalence for maxillary canine impaction. Kamilogu and Kelahmet 12 performed a study to evaluate the prevalence of impacted canines in a Cypriote population in Northern Cyprus and found that $3.53 \%$ of their sample had canine impactions. For the Mexican population, it was noted that the prevalence of maxillary canine impaction was $6.04 \% .^{13}$ While a study made by Tassara et al. ${ }^{14}$ to estimate the maxillary canine impactions in Puerto Rica showed 3.2\% prevalence.

Patil et al. ${ }^{15}$ stated a prevalence of $2.78 \%$ in west India and Sridharan et al. ${ }^{16}$ found a $3 \%$ prevalence for impacted maxillary canine. Meanwhile, researchers concluded that the prevalence of impacted maxillary canine was $0.93 \%$ among central Indian population. ${ }^{17}$ Kifayatuallah et al. ${ }^{18}$ found maxillary impacted canines in 20 (4\%) of examined Pakistani patients. An investigation of 580 Bangladeshi radiographic records found that only $7(1.2 \%)$ radiographs had impacted maxillary canines. ${ }^{19}$ Piya et al. ${ }^{20}$ estimated that for all the 550 patients treated in Kathmandu's tertiary care dental hospital, the canine impaction prevalence was $5.6 \%$. 
Melha et al. ${ }^{21}$ assessed canine tooth impaction among the population of Riyadh in Saudi Arabia, analysed 2157 patients' panoramic radiographs and found canine impaction in 79 patients $(3.65 \%)$. According to another Saudi study the prevalence of impacted maxillary canines in Najran, a south western region in Saudi Arabia, was $4.95 \% .^{22}$ In the United Arab Emirates, Abutayyem et al. $^{23}$ inspected panoramic radiographs for impacted maxillary canines and reported a prevalence of $1.7 \%$. In Southern Jordan population, a research showed that the prevalence of maxillary canine impaction was $4.73 \%{ }^{24}$ while Mustafa and Abuaffan 25 found the prevalence among Khartoum university students in Sudan to be $2 \%$. In Yemen, Al-Motareb et al. ${ }^{26}$ inspected 5287 patients out of which 188 patients $(3.55 \%)$ were confirmed to have impacted canines in Sana'a city. An investigation in Ramadi city in Iraq showed $4.6 \%$ prevalence for maxillary canine impaction. ${ }^{27}$ Another Iraqi study reported a lower prevalence of $2.7 \%$ in Al-Basrah city. ${ }^{28}$

The percentage of impacted maxillary canines among females in this study was $63.76 .1 \%$ and $36.24 \%$ among males with a ratio of (1.75:1). A significant relation between gender and maxillary canine impaction was present denoting that females have higher prevalence of maxillary canine impaction than males which agree with most of the studies about impacted maxillary impaction. Altaee 27 showed in her research on patients from Ramadi city in Iraq, that female: male ratio was 2:1. Topkara and Sari ${ }^{29}$ reported that the prevalence ratio for Turkish females was higher than males (1.3:1). Sridharan et al. ${ }^{16}$ stated a prevalence of $2.6 \%$ in males and 3.6 $\%$ in females, which agreed with what was reported by the Saudi research on Riyadh population having higher percentage in females $(3.85 \%)$ than in males $(2.88 \%)^{21}$, the Pakistani study that found a high ratio in female when compared to male $(1.85: 1)^{18}$, and the Indian investigation that noted that canine impaction in the maxillary arch was higher in females $(3.6 \%)$ than in males $(2.3 \%){ }^{15}$ In the Greek population, the prevalence female: male ratio was $2.4: 1{ }^{8}$ Several authors explained the higher female: male ratio for maxillary canine impaction resulted from the higher percentage of females who seek dental treatment, difference in growth pattern between the two, and the smaller arch width in females in comparison to males could participate in this outcome. ${ }^{4,21,22,30}$ In contrary, the Emirati study reported that the number of males (113 patients) with maxillary canine impaction was more than three times the number of females (33 patients) with the explanation that male patients visiting the clinic are much higher than female patients. ${ }^{23}$ Other studies recorded that there was no gender difference regarding the maxillary canine impaction. ${ }^{17,29}$

The current study showed that unilateral maxillary canine impactions were seen in $82.1 \%$ of radiographs resulted in a significantly higher percent than the bilateral impactions $17.9 \%$. These results are compatible with other studies reporting that most of the maxillary canine impactions occur unilaterally. $8,9,15,17,23$ Sajnani and King 30 established a ratio of $17.1 \%$ for bilateral impactions in Chinese children which is approximately the same ratio mentioned in this study. On the other hand, different ratios were found by other researchers. The study on the Indian population reported a $6 \%$ bilateral impaction for maxillary canine $^{15}$ and Lazim ${ }^{28}$ in his study on Iraqi patients found a $5.7 \%$ prevalence for bilateral maxillary canine impaction which was lower than the one reported in this study.

Many studies reported that maxillary canine impaction was more on the left side than right side. ${ }^{15,18,20.22 .23}$ When regarding the side 
distribution including both the unilateral and the bilateral canine impactions $(n=229)$ in the present study, 98 radiographs $(42.79 \%)$ had right side maxillary canine impactions while 172 radiographs $(75.1 \%)$ had impactions on the left side. While when including the side distribution in the unilateral canine impactions only $(82.1 \%, \mathrm{n}=188), 57$ radiographs $(24.89 \%)$ were with right-side impactions and 131 radiographs (57.2\%) were with left-side impactions. This agrees with most of studies concerning maxillary canine impaction as the Iraqi study revealed a high percent of impaction on the left side $57.1 \%$ than the right side $37.2 \% .{ }^{28}$ Also, the Indian study reported a higher prevalence on the left side $73 \%$ compared to $20 \%$ on the right side. ${ }^{15}$ However, others reported that unilateral maxillary canine impactions on the right and left sides were nearly equal. The study on the Turkish population found that the left and right percentage of impacted maxillary canine were $52.5 \%$ and $47.5 \%$ respectively. ${ }^{29}$ However, Jain and Debbarma ${ }^{17}$ concluded that the most affected side was the right side in both males and females.

In general, the results of this study coincide with most studies that investigated the impaction of maxillary canines regarding females, unilateral impaction, and the left side dominances. Although there is some difference in the percentages when comparing the results of this study to those reported by other studies, this could be due to several factors such as the racial difference in these studies, the difference in the size of the sample, difference in age range, and the variable methodology used in each study might have resulted in this variance in prevalence ratios.

The current study aids dental specialists to learn about the prevalence of maxillary canine impaction and to understand the need for early diagnosis and referral as it may prevent many complications that affect patients' aesthetic and functional occlusion, by simple preventive and interceptive measures.

\section{5 | CONCLUSIONS}

It is obvious that the prevalence of maxillary canine impaction differs considerably according to the ethnic and racial populations being studied. The prevalence of maxillary canine impaction of the Egyptian population in Alexandria city was found to be $2.96 \%$.

The canine impaction was more commonly seen in females than males, occurred more unilaterally than bilaterally, and more on the left side than the right side.

\section{STUDY LIMITATIONS}

The study sample was collected from one Egyptian city. Samples from other cities still require investigation.

\section{REFERENCES}

1) Bedoya MM, Park JH. A Review of the Diagnosis and Management of Impacted Maxillary Canines. J Am Dent Assoc. 2009; 140:1485-1493.

https://doi.org/10.14219/jada.archive.2009.009 9, PMID: 19955066.

2) Adina-Simona $C$, Mariana $P$, Alina $O$. Clinical and Statistical Study on Canine Impaction. Acta Med Marisiensis. 2013; 59(4):191-193. https://doi.org/10.2478/amma2013-0044.

3) Kerstein RB. Disocclusion time-reduction therapy with immediate complete anterior guidance development to treat chronic myofascial pain-dysfunction syndrome. Quintessence Int. 1992; 23(11):735747. PMID: $\underline{1305288}$.

4) Cooke J, Wang HL. Canine impactions: Incidence and management. Int $\mathrm{J}$ Periodont Rest Dent. 2006; 26:483-491. PMID: 17073358.

5) Haralur SB, Al Shahrani S, Alqahtani F, Nusair Y, Alshammari O, Alshenqety O. Incidence of impacted maxillary canine teeth in 
Saudi Arabian subpopulation at central Saudi Arabian region. Ann Trop Med Public Health 2017;

10(3):558-562. https://doi.org/10.4103/1755-6783.213175.

6) Becker A, Chaushu S. Etiology of Maxillary Canine Impaction: A Review. Am J Orthod Dentofacial Orthop. 2015;148: 557-567. https://doi.org/10.1016/j.ajodo.2015.06.013; PMID: 26432311.

7) Halıcıoğlu K, Çörekçi B, Irgın C. Incidence of Impacted Teeth and Transmigrated Canines - A Radiographic Study in Turkish Dental Patients. Clin Dent Res. 2012; 36(3):42-50. http://www.dishekdergi.hacettepe.edu.tr/htderg i/makaleler/20123.sayi07makale.pdf.

8) Fardi A, Kondylidou-Sidira A, Bachour Z, Parisis N, Tsirlis A. Incidence of Impacted and Supernumerary Teeth-A Radiographic Study in a North Greek Population. Med Oral Patol Oral Cir Bucal. 2011;16(1): e56-61. https://doi.org/10.4317/medoral.16.e56; PMID: 20711166.

9) Prskalo K, Zjaca K, Skaric-Juric T, Nikolic I, Anic-Milosevic S, Lauc T. The Prevalence of lateral incisor hypodontia and canine impaction in Croatian population. Coll Antropol. 2008; 32(4):1105-1109. PMID: 19149215.

10) Gashi A, Kamberi B, Ademi-Abdyli R, Perjuci F Sahatçiu-Gashi A. The Incidence of Impacted Maxillary Canines in a Kosovar Population. Int Sch Res Notices.2014;2014: 370531. https://doi.org/10.1155/2014/370531; PMID: 27355063.

11) Camilleri S. The Prevalence of Impacted Permanent Maxillary Canines in Maltese School Children: A Pilot Study. Malta Med J. 1995; 7(1):42-46. https://core.ac.uk/download/pdf/46602066.pdf. 12) Kamiloglu B, Kelahmet U. Prevalence of impacted and transmigrated canine teeth in a Cypriote orthodontic population in the Northern Cyprus area. BMC Res Notes. 2014;
7:346. https://doi.org/10.1186/1756-0500-7346; PMID: 24906489.

13) Herrera-Atoche JR, Agüayo-de-Pau MD, Escoffié-Ramírez M, Aguilar-Ayala FJ, Carrillo-Ávila BA, Rejón-Peraza ME. Impacted Maxillary Canine Prevalence and Its Association with Other Dental Anomalies in a Mexican Population. Int J Dent. 2017;2017: 7326061.

https://doi.org/10.1155/2017/7326061. PMID: 28326102.

14) Tassara G, Lopez L, Hanke R, Tumanyan S, Picon F. Prevalence of impacted maxillary canines in Puerto Rican adolescents. Int $\mathbf{J}$ Health Sci Res. 2015; 3(2):135-138. https://doi.org/10.15640/ijhs.v3n2a12.

15) Patil S, Santosh B, Khandelwal S, Maheshwari S. Prevalence of Impacted Canines in Population of Western Part of India. Univ Res J Dent. 2014;4(3):148-152. https://doi.org/10.4103/2249-9725.140672.

16) Sridharan K, Srinivasa H, Madhukar S, Sandbhor S. Prevalence of impacted maxillary canines in patients attending outpatient department of Sri Siddhartha Dental College and hospital of Sri Siddhartha University, Tumkur, Karnataka. J Dent Sci Res 2010; 1:9(2):109-117.

17) Jain S, Debbarma S. Patterns and prevalence of canine anomalies in orthodontic patients. Med Pharm Rep. 2019:92(1): 72-78. https://doi.org/10.15386/cjmed-907; PMID: 30957090.

18) Kifayatullah J, Bangash T, Ayub A, Khan D. Prevalence and Patterns of Impacted Maxillary Canine in a Peshawar sample. Pak Oral Dent J. 2015; 35(1):57-61. http://podj.com.pk/archive/March_2015/PODJ15.pdf.

19) Alif SM, Haque S, Nimmi N, Ashraf A, Khan SH, Khan MH. Panoramic Radiological Study to Identify Locally Displaced Maxillary Canines in Bangladeshi Population. Imaging 
Sci Dent. 2011; 41(4):155-159 https://doi.org/10.5624/isd.2011.41.4.155;

PMID: 22232724.

20) Piya A, Shrestha BV, Khapung A, Bhattarai P. Prevalence and Pattern of Canine Impaction and Its Associated Anomalies among Orthodontic Patients Attending Tertiary Care Dental Hospital in Kathmandu. Orthod J Nepal. 2020;10(1):6-10. https://doi.org/10.3126/ojn.v10i1.30996.

21) Melha SB, Alturki S, Aldawasri G, Almeshari N, Almeshari S, Albadr K. Canine impaction among Riyadh population: A single center experience. Int J Oral Health Sci. 2017; 7:93-95.

https://doi.org/10.4103/ijohs.ijohs_52_17.

22) Alyamia B, Braimahb R, Alharieth $S$. Prevalence and pattern of impacted canines in Najran, South Western Saudi Arabian population. Saudi Dent J. 2020; 32(6): 300305.

https://doi.org/10.1016/j.sdentj.2019.10.002; PMID: 32874070.

23) Abutayyem H, Fouly F, Awny N, ElMarsafawy T, Ghanem RH. Prevalence of Impacted Maxillary Canines and its Associated Anomalies among a Dental College Patients. EC Dent Sci. 2019; 9: 2048-2058. https://www.ecronicon.com/ecde/pdf/ECDE18-01140.pdf.

24) Rahamneh A, Al-Weshah M, Ghozlan M, Smadi H, Abu-Odeh R. Prevalence and severity of ectopic maxillary canine impaction in Southern Jordanian population: A radiographic sector analysis. J Royal Med Serv 2017;24(1):38-44. https://doi.org/10.12816/0034767.

25) Mustafa RA, Abuaffan AH. Prevalence of impacted canines among Sudanese university students. Braz Dent Sci 2014;17(4):27-33. https://doi.org/10.14295/bds.2014.v17i4.1030.

26) Al-Motareb FL, Al-Labani1 MA, AlZubair NM, Dhaifullah E. Prevalence of impacted canine among Yemen population in Sana'a city. Int J Dent Res. 2017;5(2):148-151. https://doi.org/10.14419/ijdr.v5i2.8113.

27) Altaee $\mathrm{ZH}$. Incidence of impacted maxillary canine and associated with maxillary lateral incisor anomalies in Ramadi city. Asian J Sci Technol. 2014; 5(3): 226-229. https://www.journalajst.com/sites/default/files/i ssues-pdf/1497_0.pdf.

28) Lazim AI. The Prevalence of Impacted Maxillary Canine among Iraqi Patients of AlBasrah City. J Bagh Coll Dent. 2016;28(1):7377. https://doi.org/10.12816/0024712.

29) Topkara A, Sari Z. Impacted teeth in a Turkish orthodontic patient population: prevalence, distribution, and relationship with dental arch characteristics. Eur J Paediatr Dent. 2012; 13(4):311-316. PMID: 23270290.

30) Sajnani AK, King NM. Prevalence and Characteristics of Impacted Maxillary Canines in Southern Chinese Children and Adolescents. J Invest Clin Dent. 2014; 5(1):38-44. https://doi.org/10.1111/jicd.12027, PMID: 23355390. 